\title{
To Excite, From the Traditional to the Bio-Pedagogy
}

Adriana Páez Pino, Magister ${ }^{1}$, Clara Inés Jaramillo Gaviria, Magister ${ }^{2}$, and Edwin Francisco Forero García, Magister $^{1}$

${ }^{1}$ Fundación Universitaria los Libertadores, Colombia, decaing @ libertadores.edu.co

${ }^{2}$, 3 Universidad Santo Tomás, Colombia, clarajaramillo@usantotomas.edu.co, edwinforero@ usantotomas.edu.co

\begin{abstract}
Western societies are directly influenced by industrial and educational models developed and imposed by the West, are being confronted with themselves from their mother cell: the individual. Every day, the reality of an environment or a culture requires the human being other than raise his hand and his voice in order to explain and assert their difference, without guarantees to be heard, that is why the processes of formation of beings human, having lived boom of the specification and academic segmentation of knowledge, have also had to start a spin sheet themselves, taking angles and coherent strategies with individuals receiving their contents but not to apply them mechanically but precisely to articulate, dynamic setting meeting points that articulate the concepts and societies, enhancing the lifestyles of the inhabitants and users of every place on earth, with its different climates and soils, with their own abundance and wants to by stimulating and managing autopoietic learning education systems, whose maintenance involves reciprocity provided between the learner and their habitat.

Keywords - Biopedagogy, autopoietic, Learner, learning, interactions, self-management organization.
\end{abstract}

Digital Object Identifier (DOI):

http://dx.doi.org/10.18687/LACCEI2016.1.1.362

ISBN: 978-0-9822896-9-3

ISSN: 2414-6390

$14^{\text {th }}$ LACCEI International Multi-Conference for Engineering, Education, and Technology: "Engineering Innovations for Global Sustainability", 20-22 July 2016, San José, Costa Rica. 


\title{
To Excite, From the Traditional to the Bio-Pedagogy
}

\author{
Adriana Páez Pino, Magister ${ }^{1}$, Clara Inés Jaramillo Gaviria, Magister ${ }^{2}$, and Edwin Francisco Forero García, Magister ${ }^{1}$ \\ ${ }^{1}$ Fundación Universitaria los Libertadores, Colombia, decaing@libertadores.edu.co \\ 2,3Universidad Santo Tomás, Colombia, clarajaramillo@usantotomas.edu.co, edwinforero@usantotomas.edu.co
}

\begin{abstract}
Western societies are directly influenced by industrial and educational models developed and imposed by the West, are being confronted with themselves from their mother cell: the individual. Every day, the reality of an environment or a culture requires the human being other than raise his hand and his voice in order to explain and assert their difference, without guarantees to be heard, that is why the processes of formation of beings human, having lived boom of the specification and academic segmentation of knowledge, have also had to start a spin sheet themselves, taking angles and coherent strategies with individuals receiving their contents but not to apply them mechanically but precisely to articulate, dynamic setting meeting points that articulate the concepts and societies, enhancing the lifestyles of the inhabitants and users of every place on earth, with its different climates and soils, with their own abundance and wants to by stimulating and managing autopoietic learning education systems, whose maintenance involves reciprocity provided between the learner and their habitat.
\end{abstract}

Keywords - Biopedagogy, autopoietic, Learner, learning, interactions, self-management organization. 


\title{
EMOCIONAR, DE LO TRADICIONAL A LA BIOPEDAGOGÍA
}

\author{
Adriana Páez Pino, Magister ${ }^{1}$, Clara Inés Jaramillo Gaviria, Magister ${ }^{2}$, and Edwin Francisco Forero García, Magister ${ }^{1}$ \\ ${ }^{1}$ Fundación Universitaria los Libertadores, Colombia, decaing@libertadores.edu.co \\ ${ }^{2,3}$ Universidad Santo Tomás, Colombia, clarajaramillo@usantotomas.edu.co, edwinforero@usantotomas.edu.co
}

\begin{abstract}
Resumen-Las sociedades actuales directamente occidentales o ahora influidas por los modelos industriales y educativos que desarrollados e impuestos por occidente, están siendo confrontadas con ellas mismas desde su célula madre: el individuo. Cada día, la realidad de un entorno o una cultura obliga al ser humano diferente a levantar su mano y su voz en aras de explicar y hacer valer su diferencia, sin garantías de ser escuchado, es por esto que los procesos de formación de los seres humanos, tras haber vivido el auge de la especificación y sectorización académica del conocimiento, han tenido también que empezar a dar una vuelta de hoja a sí mismos, adoptando ángulos y estrategias coherentes con los individuos que reciben sus contenidos pero no para aplicarlos de manera mecánica sino precisamente para articularlos, estableciendo puntos de encuentro dinámicos que articulen los conceptos y las sociedades, potenciando los estilos de vida de los habitantes y usuarios de cada lugar de nuestro planeta, con sus diversos climas y suelos, con sus propias abundancias y carencias, a través de la estimulación de la aprendiencia y la gestión de sistemas educativos autopoiéticos, cuyo sostenimiento implique la reciprocidad entre lo brindado al aprendiente y su hábitat.
\end{abstract}

Keywords- Biopedagogía, autopoiesis, aprendiente, aprendiencia, interacciones, autogestión, autoorganización.

Abstract- Western societies are directly influenced by industrial and educational models developed and imposed by the West, are being confronted with themselves from their mother cell: the individual. Every day, the reality of an environment or a culture requires the human being other than raise his hand and his voice in order to explain and assert their difference, without guarantees to be heard, that is why the processes of formation of beings human, having lived boom of the specification and academic segmentation of knowledge, have also had to start a spin sheet themselves, taking angles and coherent strategies with individuals receiving their contents but not to apply them mechanically but precisely to articulate, dynamic setting meeting points that articulate the concepts and societies, enhancing the lifestyles of the inhabitants and users of every place on earth, with its different climates and soils, with their own abundance and wants to by stimulating and managing autopoietic learning education systems, whose maintenance involves reciprocity provided between the learner and their habitat.

Keywords - Biopedagogy, autopoietic, Learner, learning, interactions, self-management organization.

\section{INTRODUCCIÓN}

En el presente escrito pretendemos señalar algunos elementos que amplían nuestro horizonte de sentido para comprender una nueva visión pedagógica que responda a las

Digital Object Identifier (DOI): http://dx.doi.org/10.18687/LACCEI2016.1.1.362 ISBN: 978-0-9822896-9-3

ISSN: $2414-6390$ exigencias, retos y necesidades educativas del mundo que vivimos.

Con el fin de alcanzar el cometido planteado, se propone el siguiente recorrido: en primer lugar, explicitar la dicotomía destructiva que se evidencia entre el mundo de la vida y la propuesta educativa de la cultura occidental; en segundo lugar, explicar los cambios y la transformación que enfrenta la educación para el nuevo milenio; y, finalmente, relacionar los dos temas anteriores con el fin de señalar algunos elementos que articulen el proceso académico con el entramado social y la práctica profesional.

\section{RELACIONES DE ORDEN}

Con el fin de asegurar los logros de la cultura, el hombre ha creado estrategias de enseñanza y aprendizaje, que tienen como objetivo transmitir de generación en generación, ideales, valores, técnicas y demás productos culturales que han posibilitado a la comunidad su desarrollo y desenvolvimiento en el planeta. Es pues, por medio de la educación que se asume como propia la identidad cultural que caracteriza la comunidad a la que se pertenece.

El educar se constituye en el proceso en el cual el niño o el adulto convive con otro y al convivir con el otro se transforma espontáneamente de manera que su modo de vivir se hace progresivamente más congruente con el del otro en el espacio de convivencia. El educar ocurre, por lo tanto, todo el tiempo; de manera recíproca, como una transformación estructural contingente a una historia en el convivir en el que resulta que las personas aprenden a vivir de una manera que se configura según el convivir de la comunidad donde viven. La educación como "sistema educacional" configura un mundo y los educandos confirman en su vivir el mundo que vivieron en su educación. Los educadores, a su vez, confirman el mundo que vivieron al ser educados en el educar [6].

La cultura occidental se ha caracterizado por reflexionar sobre la tradición, el hombre y la educación para asegurar los logros obtenidos y proyectar el progreso de su identidad. De ahí que esta cultura, desde sus orígenes en la Grecia Antigua, haya dado un lugar preeminente al conocimiento y a la educación, pues considera que su tarea es develar los ideales de hombre y de comunidad (thelos) que proyecta, y los modos operativos para conseguirlos (paideia) [10]. Por consiguiente, en la tradición occidental se ha tratado de evidenciar, por un

14 ${ }^{\text {th }}$ LACCEI International Multi-Conference for Engineering, Education, and Technology: "Engineering Innovations for Global Sustainability", 20-22 July 2016, San José, Costa Rica. 
lado, el ser y el deber ser del hombre, en tanto hacedor y hechura cultural; y por otro lado, establecer las metodologías, didácticas y áreas de conocimiento necesarias para consolidarla y perpetuarla.

\section{INTERACCIONES DESTRUCTIVAS}

A partir de los años 70s, el mundo experimenta transformaciones que vuelven la mirada a la reflexión de las relaciones entre educación, conocimiento y desarrollo. Fruto de ésta nueva comprensión se convoca, en el año de 1990, a representantes de 92 países en la ciudad de Jomtien (Tailandia) para afrontar el problema de la exclusión en educación, y suscriben la Declaración Mundial sobre Educación para Todos. Los acuerdos y compromisos fijados en esa ocasión, fueron retomados por el Fondo Monetario Internacional y el Banco Mundial para fijar políticas en pro de la competitividad, con el objeto de ofrecer un mejor producto o servicio (la educación) pensando desde las exigencias que trae la globalización. Este llamado, demandó de sus países miembros, y más específicamente de Latinoamérica, una reestructuración de la legislación educativa para promover la calidad y la equidad en la prestación del servicio.

En éste contexto, los gobiernos direccionaron una propuesta de renovación legislativa que abrió el camino para que el cambio abarcara todo el ámbito nacional de la educación, a nivel estatal y privado, que se concretó en la Ley General de Educación que se aprobó durante los años 90s en Chile, México, Argentina, Colombia, España, etc. Un ejemplo de este proceso se refleja en los argumentos esgrimidos en la ponencia, que realizaron ante el senado colombiano los parlamentarios Dájer Chadid \& Hernández Aguilera al presentar el Proyecto de la Ley 115 en 1993:

El nuevo modelo de economía internacional exige una mano de obra competente que es preciso intensificar especialmente en ciertas regiones en donde el acceso a la educación, con el criterio de que es una inversión altamente rentable tanto social como económicamente, y es preciso considerarla como una importante capitalización a largo plazo con una de las más bajas depreciaciones, según el estudio elaborado por la misión Chenery. Es preciso entonces que el hombre colombiano se adapte a esas circunstancias cambiantes de la humanidad y que requieren la capacitación técnica para el trabajo y la competitividad [3].

Dicha Ley General de Educación estandarizó los currículos y fundamentó el proceso pedagógico en el concepto de persona humana y de su dignidad, desde la propuesta de formación integral; pero al hacer una lectura minuciosa de la exposición de los motivos que la inspiraron, de los objetivos y fines de la educación, se detecta una orientación más dirigida a intereses económicos y políticos que formativos $\mathrm{y}$ pedagógicos. Y menos aún hacia responder por las necesidades propias de cada país donde se implementó.

Esta reinterpretación impuesta orienta, enfoca y estandariza el proceso educativo hacía la formación de ciudadanos, trabajadores competentes, que respondan a los retos culturales de una sociedad-capitalista-globalizada de manera competitiva; en detrimento de lo humano y propio en cada persona y de su formación integral desde la alteridad.

Si la educación media y superior en Chile se fundan en la competencia, en la justificación engañosa de ventajas y privilegios, en una noción de progreso que aleja a los jóvenes del conocimiento de su mundo, limitando su mirada responsable hacia la comunidad que los sustenta, la educación media y superior de Chile no sirve a Chile ni a los chilenos. Si la educación media y superior nos invita a la apropiación, a la explotación de mundo natural y no a nuestra coexistencia armónica con él, esa educación no sirve ni a Chile ni a los chilenos. [6].

Esta propuesta educativa impuesta, homogeneizadora, reduccionista y utilitarista que se impone a los países occidentales no les sirve, ni a sus habitantes ni a la misma cultura occidental, pues no responde a la naturaleza y situaciones sociales de inequidad, pobreza, corrupción, violencia, discriminación que la perturban y por ende a los que la vivimos o mejor padecemos [6].

Por ello, podemos afirmar que la dicotomía que se evidencia entre el mundo de la vida y las propuestas políticas, económicas y educativas de la cultura occidental son interacciones destructivas, pues no se abren a las perspectivas de sus propias dinámicas para autoorganizarse y autogestionarse.

Todo cambio estructural ocurre en un ser vivo necesariamente acotado por la conservación de su autopoiesis, y serán perturbaciones aquellas interacciones que gatillen en él cambios estructurales compatibles con dicha conservación, e interacciones destructivas las que no [11].

\section{AUTOPOIÉSIS}

La cultura adquirida no constituye una camisa de fuerza, paradójicamente, el ser humano posee la capacidad de recrear y reorientar la cultura a través del aprendizaje social y la biopedagogía. Es precisamente el presente que vivimos el momento oportuno para generar interacciones que disparen un cambio estructural hacia nuevas formas de comprender $y$ actuar en el mundo.

En el caso particular de las culturas como linajes humanos de maneras de convivir, se produce un cambio en

$14^{\text {th }}$ LACCEI International Multi-Conference for Engineering, Education, and Technology: "Engineering Innovations for Global Sustainability", 20-22 July 2016, San José, Costa Rica. 
una comunidad humana particular solo cuando una nueva manera de vivir, como una red de conversaciones, comienza a conservarse de manera transgeneracional y eso comienza a suceder cada vez que una configuración en el emocionar, y por lo tanto, una nueva configuración en el actuar, comienzan a ser parte de la manera corriente de incorporación cultural de los niños de esa comunidad, y estos la aprenden al vivirla [5].

La sociedad del conocimiento, fundamentada en los trazos deterministas del pensamiento reduccionista y simplificador presentes en la pedagogía y en los currículos actuales, supone un esfuerzo casi desesperado para hacer simétricos los controles en la esfera del conocimiento [1], por ello hoy en día son tan importantes las medidas econométricas, como por ejemplo las pruebas Saber, que se aplican en todos los niveles de educación. Pero esta perspectiva desconoce que el proceso de aprendizaje es parte de la vida misma, entendida esta como proceso autopoiético dado que es simultáneamente la vida como voluntad, deseo y emoción, la vida como el proyecto de realidad que cada uno es y construye de sí. Se aprende durante toda la vida y mediante todas las formas de vivir [1]

Esta comprensión exige que se resignifique el rol y los conceptos: enseñanza, aprendizaje, comunidad académica, etc., hacia una propuesta abierta de la aprendiencia, el aprendiente y las organizaciones aprendientes (VIDA + academia + mundo laboral + sociedad $=$ cultura aprendiente $)$. $\mathrm{Y}$, por ende, un cambio paradigmático en las propuestas y significaciones de categorías tales como: estudiante, docente, currículo, áreas de conocimiento o epistemologías, metodología, didáctica, etc. [1]. Por ello creemos que:

Se requiere comprender que cada ser humano es un cuerpo subjetivo y desde su corporeidad conoce, quiere, valora, desea, imagina, siente, reflexiona sobre sí mismo, y realiza representaciones cognoscitivas, volitivas, valorativas y afectivas. Es decir, el cuerpo personal, además de experimentar el mundo de la vida, tiene la capacidad de reflexión, de volver sobre las vivencias para expresarlas y dotarlas de sentido. Por ello, consideramos, como afirma Assmann: que el cuerpo es, desde el punto de vista científico, la instancia fundamental para articular conceptos centrales para una teoría pedagógica. Sólo una teoría de la corporeidad puede proporcionar las bases para una teoría pedagógica [1].

Se requiere dejar claro que las epistemologías basadas en una concepción mecanicista son inadecuadas para la comprensión del mundo, pues se requieren epistemologías que den cuenta del entramado de la compleja realidad, y de sus dinámicas. Por lo tanto, una sociedad académica aprendiente requiere del diseño de un currículo flexible y morfogenético que permita comprender la complejidad que contiene el entramado del mundo [1] y que la realidad no puede ser controlada porque no está hecha solo de inmediatez, dado que está mediada por la incertidumbre.

Se requiere comprender que vivir es dotar de sentido el mundo vivido y en que se vive, por lo cual la construcción de sentido no pertenece solo al ámbito académico sino que es un proceso permanente que se construye, se vive y se rehace a lo largo de la existencia individual (existencia personal) y grupal (existencia sociocultural) [4]. Cuando comprendemos esto percibimos que el proceso de aprendizaje debe dotar de sentido los contenidos que se trabajan en el aula de clase, no desde la perspectiva del currículo o los estándares de competencias sino desde la vida personal y social del estudiante, dado que se aprende para la vida, en la vida y viviendo.

Se requiere comprender que el estudiante no es una tabula rasa en la que hay que tallar conocimiento y que el docente no es el poseedor del conocimiento. En el mundo que conocemos no hay ningún ser humano que posea todo o ningún conocimiento; por lo cual el proceso de aprendizaje, en el ámbito académico, cambia sustancialmente y se convierte en organizaciones aprendientes.

Se requiere transformar el entorno académico anquilosado, forzado e impuesto de la escuela tradicional, por espacios de amor, placer y juego donde se aprenda a vivir con y para construir una sociedad solidaria que se organice a sí misma, donde el emocionar personal esté conectado con el emocionar de la vida misma y el entramado del mundo.

La diferencia que existe entre prepararse para devolver al país lo que uno ha recibido de él trabajando para acabar con la pobreza, y prepararse para competir en el mercado ocupacional, es enorme. Se trata de dos mundos completamente distintos. Cuando yo era estudiante, como ya lo dije, deseaba retribuir a la comunidad lo que de ella recibía, sin conflicto, porque mi emoción y mi sensibilidad frente al otro, y mi propósito o intencionalidad respecto del país, coincidian. Pero actualmente esta coincidencia entre propósito individual y propósito social no se da porque en el momento en que uno se forma como estudiante para entrar en la competencia profesional, uno hace de su vida estudiantil un proceso de preparación para participar en un ámbito de interacciones que se define en la negación del otro bajo el eufemismo: mercado de la libre y sana competencia [6].

Se requiere comprender que si bien algunos de los avances científicos y tecnológicos que trae la llamada sociedad del conocimiento han sido de gran ayuda para brindar bienestar a la humanidad, la mayoría han estado al

$14^{\text {th }}$ LACCEI International Multi-Conference for Engineering, Education, and Technology: "Engineering Innovations for Global Sustainability”, 20-22 July 2016, San José, Costa Rica. 
servicio de la sociedad de consumo y el libre mercado; un cambio paradigmático de la educación, desde la perspectiva de biopedagogía, brinda la posibilidad de relacionar íntimamente el potencial innovador del conocimiento con la propia esencia creadora de la vida [1]

\section{INTERACCIONES QUE ACTIVEN UN CAMBIO ESTRUCTURAL COMPATIBLE}

La concepción mercantilista, utilitarista y competitiva del educando, de la educación, del empleado y de la empresa, se ajustan a un modelo en el que sobrevive el más fuerte, donde se aprovechan unos de otros enfrentándose a su propia destrucción en un marco de libre mercado y "sana competencia”. Este panorama se avista en una sociedad de producción y consumo que genera y entrega todo a toda hora para satisfacer necesidades creadas por el mismo sistema de mercado, sin considerar el costo ecológico ni social de este peligroso entramado de negocio que encuentra su sustento en el recurso natural, el cual se debilita día a día en beneficio de la comodidad de la raza humana.

La sana competencia no existe. La competencia es un fenómeno cultural y humano y no constitutivo de lo biológico. Como fenómeno humano la competencia se constituye en la negación del otro. Observen las emociones involucradas en las competencias deportivas. En ellas no existe la sana convivencia porque la victoria de uno surge de la derrota del otro, y lo grave es que, bajo el discurso que valora la competencia como un bien social, uno no ve la emoción que constituye la praxis del competir, emoción que constituye las acciones que niegan al otro [6].

Lo dado es la oportunidad de generar interacciones que propicien un cambio estructural compatible para la preservación del hombre y el mundo. Esta congruencia se entiende como un encuentro necesario entre sociedades que construyan un entramado donde se responda preguntas básicas, como ¿para qué nos educamos?, ¿cómo nos educamos?, ¿qué sociedad queremos?, cuyas respuestas persigan objetivos comunes, donde la competencia sea para construir y no para destruir y negar las acciones del otro.

El conocimiento adquirido por la humanidad, justificado por la sana competencia y el libre mercado, ha llegado a generar los más grandes avances para el desarrollo de la tecnología, hechos que sistematizados a maneras de experiencias de aprendizaje pueden significar las herramientas que nos llevan a crear un entorno de respeto $y$ de reconstrucción de nuestro entorno. Nos encontramos situados en una época en la que es posible, gracias a las comunicaciones, el establecimiento de redes mediante las cuales se comparten la información y las experiencias, se envían millones de mensajes por segundo, se tiene acceso a una base de datos estimada en treinta y cinco Zettabytes en internet. Estas herramientas direccionadas en torno a generar una conciencia ecológica, como una organización que surge de una sensibilidad solidaria, para recuperar nuestro entorno crecerán en cada una de las redes existentes, de acuerdo con las leyes de los campos mórficos. De esta manera las tecnologías de la información y las comunicaciones son útiles para un propósito en el que renace el espíritu y la conciencia por conservar la naturaleza. Es claro que lo importante es sembrar esa semilla, establecer una estructura de la información y esta simplemente llegará a cambiar la conducta de cada ser humano de este entramado, independiente de la función que realice en la sociedad.

Si la conducta es efectivamente gobernada por campos mórficos, cuando algunos miembros de una especie adquieren una nueva pauta de conducta y por lo tanto un nuevo campo por ejemplo aprendiendo una nueva astucia- los otros deben tender a aprender lo mismo con más rapidez, incluso en ausencia de cualquier medio conocido de conexión o comunicación. Cuantos más sean los miembros de la especie que realizan ese aprendizaje, mayor será este efecto en todo el mundo [10].

La idea de una sociedad aprendiente, que se apoya en la sistematización de experiencias y consciente de las transformaciones que se requieren para llegar a la sostenibilidad de este gran entramado natural que compartimos, se fundamenta desde la propuesta de una interacción entre sociedad de conocimiento y la sociedad productiva. Una sociedad que aprende mediante la interacción con su entorno, representada en un convivir con la naturaleza, entendiéndola y respetándola para comprender sus certezas y sus incertidumbres sin destruir, ni alterar los ecosistemas por el solo hecho de perseguir un conocimiento especializado y específico para el confort y conveniencia de la especie humana.

Educar es crear, realizar, y validar en la convivencia, un modo particular de convivir. Esto siempre se realiza en una red de conversaciones que coordina el hacer y el emocionar de los participantes. En un país, la tarea de cualquier actividad educativa es cumplir este quehacer en la formación de los ciudadanos del país. En un país de intención democrática, esto significa entregar a cada ciudadano elementos para un quehacer autónomo, social $y$ ecológicamente responsable [7].

Esta sociedad moderna que ha generado transiciones nunca antes documentadas, de forma tan rápida y puesto a la ciencia y la tecnología al servicio del desarrollo económico del planeta, cuenta hoy con las herramientas necesarias para establecer una convivencia solidaria de manera natural sin considerar, ni validar la destrucción para su supervivencia [1] Esta nueva actividad humana asociada a los avances tecnológicos y al desarrollo sistemático de experiencias que flexibilizan y se adaptan, para conseguir una sociedad

$14^{\text {th }}$ LACCEI International Multi-Conference for Engineering, Education, and Technology: "Engineering Innovations for Global Sustainability”, 20-22 July 2016, San José, Costa Rica. 
ecológica se vinculan directamente a las transformaciones continuas que se requieren en la formación de los seres humanos que componen la sociedad, a quienes podemos llamar aprendientes. Son ellos quienes se encargarán de establecer un dialogo simbiótico entre el conocimiento y la producción.

Todos los sistemas biológicos (los organismos y las organizaciones sociales o ecológicas de organismos) son capaces de cambios adaptativos. Pero los cambios adaptativos revisten muchas formas, tales como la respuesta, el aprendizaje, la sucesión ecológica, la evolución biológica, la evolución cultural, etcétera, de acuerdo con la dimensión y la complejidad del sistema que elijamos considerar. Cualquiera sea el sistema, el cambio adaptativo depende de circuitos de retroalimentación, sean los que proporciona la selección natural o los que resultan del refuerzo individual. En todos los casos, pues, ha de existir un proceso de ensayo y error y un mecanismo de comparación [2]

De lo anterior podemos inferir una propuesta de sociedad aprendiente que concilia entre la academia y el sector económico, en donde la información y el conocimiento son realmente la base que fundamenta la producción económica mundial, todo esto construido sobre el sistema de educación como pilar [1]. Sin embargo, si solo se da una mirada a indicadores de economía y conocimiento, por un lado, podemos distraernos asombrándonos con incontables avances tecnológicos que han impulsado la producción mundial, controlando enfermedades, acelerando procesos y generando grandes capitales económicos. Por el otro lado, encontramos una ecología y un medio ambiente seriamente afectados, lo cual habla en buena forma del poco dialogo que hemos tenido con nuestro entorno para realizar nuestros sueños de progreso. Desde la educación hemos creado y vuelto a crear profesiones que con conocimientos y tareas específicas generan simetrías $\mathrm{y}$ encuentran soluciones sin considerar los verdaderos impactos en nuestra "casa común" como la llama el Papa Francisco en su carta encíclica Laudato SI’ [9].

En el proceso educativo no solo se debe ver como un acto de aprendizaje el ocurrido dentro de un salón de clase de una escuela, colegio o universidad, este es un proceso que se da en cada ser vivo en su contacto con el entorno, en la vivencia y asimilación de sus propias experiencias y en la transmisión de estas a otros. Por esta razón la actividad del mediador y del aprendiente es alternativa. La educación como proceso autopoiético se presenta de manera coordinada o descoordinada y simétrica o disimétrica, pero en cada momento de la existencia. El objetivo de la sociedad es entonces mediar por un profesional que responda de manera ética, ecológica y coherente, que reconozca su responsabilidad sabiendo que cada uno de sus actos afecta el mundo. Desde la sociedad productiva reconocer que el empleado no es un aprendiente terminado, sino que aprovecha y respeta las estructuras de aprendizaje que se han formado en él a lo largo de experimentar la vida. De esta manera, la aprendiencia crece en experiencias e interacciones que gatillan un cambio estructural compatible hacia una sociedad aprendiente.

La concepción que podamos tener de la naturaleza humana afecta a todos los aspectos de nuestra vida, desde la forma en que educamos a nuestros hijos hasta las ideas políticas que defendemos. Sin embargo, en un momento en que la ciencia está avanzando espectacularmente en estos temas, muchas personas se muestran hostiles al respecto. Temen que los descubrimientos sobre los patrones innatos del pensar y el sentir se puedan emplear para justificar la desigualdad, subvertir el orden social, anular la responsabilidad personal y confundir el sentido y el propósito de la vida [8].

Por último, después de este recorrido y de adelantar nuestra investigación, nos cuestionamos y tratamos de dar respuesta a nuestra realidad en el aula, en los aspectos pedagógicos que podemos brindar a las nuevas generaciones.

¿Es indispensable que todos nuestros jóvenes realicen el bachillerato y se profesionalicen, o se puede soñar con una cultura educativa que responda a las necesidades e inquietudes de cada aprendiente, región, ciudad, cultura, género, etc.?

¿Cómo salirnos de los ismos epistemológicos que atraviesan los currículos, para elaborar propuestas de espacios académicos que respondan a las inquietudes e incertidumbres del aprendiente y el mundo de la vida, y por qué no, del mismo conocimiento?

\section{REFERENCES}

[1] Assmann, H. Placery ternura en la educación. hacia una sociedad aprendiente. Madrid: Narcea. P 11, 17, 27,32, 43, 68, 119, (2002).

[2] Bateson, G. Pasos hacia una ecología de la mente. Buenos Aires: LohléLumen. P 193, (1998).

[3] Dájer Chadid, G., \& Hernández Aguilera, G.. Proyecto de Ley 115 de 1993. Gaceta del Congreso. Bateson , p 21, (24 de noviembre de 1993)

[4] Gutiérrez P., F. En busca del sentido. San José de Costa Rica: Doctorado de la tercera cultura. P 5, (2006).

[5] Maturana Romesín, H., \& Verden-Zôller, G. Amor y juego. Fundamentos olvidados de lo humano. Desde el patriarcado a la democracia. Chile: J.C. Sáez. p 49, (2003).

[6] Maturana, H. Emociones y lenguaje en educación y política. Chile: Dolmen Ensayos. P 6, 18, 21, 22, XV (2001).

[7] Maturana R., H. Transformación en la convivencia. Santiago de Chile: Dolmien Ensayos. P 147, (1998).

[8] Pinker, S. La tabla rasa. Negación moderna de la naturaleza humana. Barcelona: Paidós. P 4, (2003).

[9] Santo Padre, F. Carta Encíclica LAUDATO SI'. Sobre el cuidado de la casa común. Ciudad del Vaticano: Mensajero. P 12, (2015).

[10]Sheldrake, R. El renacimiento de la naturaleza. Barcelona: Paiodós, P 24, $56,(1994)$.

[11]Varela G., F., \& Maturana R., H. El árbol de conocimiento. Chile: Lumen. P 67, (2003).

$14^{\text {th }}$ LACCEI International Multi-Conference for Engineering, Education, and Technology: "Engineering Innovations for Global Sustainability”, 20-22 July 2016, San José, Costa Rica. 